\title{
Relation between exposure to respirable silica dust and silicosis in a tungsten mine in China
}

\author{
D Pang, S C Fu, G C Yang
}

\begin{abstract}
To estimate the quantitative relation between exposure to respirable silica dust and risk of an attack of silicosis, 1151 workers exposed to silica dust and employed from 1958 to 1987 in a tungsten mine in China were investigated. The results showed that the ratio of respirable silica dust concentration to total silica dust concentration was 0.529 . Then, the total silica dust concentration in historical surveillance and monitoring data was converted to respirable silica dust concentration. The free silica content in respirable dust determined by $x$ ray diffraction averaged $24 \cdot 7 \%$. Multiple logistic regression was used for the dichotomous dependent variables (presence or absence of silicosis). The independent variables in the multiple logistic regression with presence of silicosis as the dependent variable were age when first exposed, tuberculosis (presence or absence), and cumulative exposure to respirable silica dust. The partial regression coefficient of individual cumulative exposure was estimated as 0.079 . It implied a positive association between exposure to respirable silica dust and risk of an attack of silicosis. The exposure limit for respirable silica dust was estimated as $0.24 \mathrm{mg} / \mathrm{m}^{3}$ under given conditions.
\end{abstract}

Respirable dust is defined as that reaching the alveoli and is assumed to be associated more with pneumoconiosis than is total dust. As a result, health standards for respirable dust have been introduced by many countries-for example, America, Japan, Australia-in the context of prevention of pneumoconiosis. We are presently conducting a retrospective epidemiological study of selected workers from a tungsten mine in China to establish the quantitative relation between exposure to respirable silica dust and silicosis. The aim of the present study is to provide epidemiological evidence for setting and

Institute of Occupational Medicine, Beijing 100050, People's Republic of China

D Pang, S C Fu, G C Yang revision of the exposure limit for respirable silica dust.

\section{Subjects and methods}

SUBJECTS

The study took advantage of both historical surveillance and monitoring data collected in the period from 1958 to 1987.

Men eligible for inclusion in the study were underground miners hired from 1958 to 1987 inclusive, without exposure to dust before 1958 . Those who were previously exposed to other kinds of dusts, such as tungsten, were excluded. The criteria for inclusion were met by 1151 men.

EXPOSURE AND ESTIMATION

Information about the mine and the estimation of individual exposures by extrapolation based on fixed point membrane filter measurement has been published elsewhere. The total and respirable silica dust concentrations at workplaces of major job titles were measured. The free silica content in respirable dust was determined by $x$ ray diffraction.

\section{STATISTICAL METHODS}

The relation between respirable dust concentration and total dust concentration was assessed by a linear regression model. The relation between silicosis and cumulative respirable silica dust concentration was determined by multiple logistic linear regression with the logist procedure of the SAS package. ${ }^{1}$

\section{QUALITY CONTROL MEASURES}

Quality control measures were instituted to ensure the quality of information collected. All data were checked when completed to establish that all items had been attempted. When completed all dat $\%$ were checked by computer procedures to ensure no logistic mistakes. Then all data were checked manually to ensure no entry errors. An airflow calibrating meter was used to calibrate the flow of samplers.

\section{Results}

RESPIRABLE AND TOTAL DUST CONCENTRATIONS

The figure shows the correlation between respirable and total dust concentrations at workplaces in the underground mine. A linear trend was found. Table 


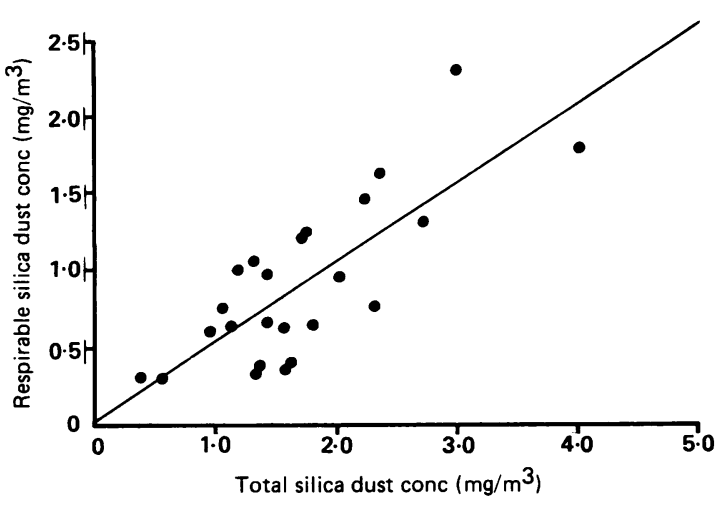

Regression of respirable and total dust concentrations.

1 shows the $t$ test statistics of regression. The regression coefficient was $0.529(\mathrm{p}<0.001)$. It implied that the respirable dust concentration correlated with the total dust concentration. According to the regression coefficient, the ratio of respirable dust concentration to total dust concentration was 0.529 . Therefore the respirable dust concentration was estimated based on total dust concentration in historical surveillance and monitoring data.

FREE SILICA CONTENT OF RESPIRABLE DUST

The arithmetic mean of six samples was $24 \cdot 7 \%$.

RESPIRABLE SILICA DUST CONCENTRATION AND SILICOSIS

Table 2 presents the results of the multiple logistic regression with presence of silicosis as the outcome. The partial regression coefficient between the cumulative exposure to respirable silica dust and silicosis was statistically significant $(\beta=0.079$, $\mathrm{p}<0.05)$ after allowing for the age of first exposure and tuberculosis (TB). The probability of develop-

Table 1 Regression analysis of respirable and total dust concentrations

\begin{tabular}{lllll}
\hline $\begin{array}{l}\text { Independent } \\
\text { variable }\end{array}$ & $\begin{array}{l}\text { Dependent } \\
\text { variable }\end{array}$ & $\begin{array}{l}\text { No of } \\
\text { samples }\end{array}$ & $t$ Value & $\begin{array}{l}\text { PValue } \\
\text { (one sided) }\end{array}$ \\
\hline Respirable dust & Total dust & 25 & $15 \cdot 247$ & 0.000 \\
\hline
\end{tabular}

Table 2 Linear multiple logistic regression with presence of silicosis as outcome and with age of first exposure, $T B$, and cumulative exposure to respirable silica dust as independent variables

\begin{tabular}{lrrr}
\hline Variable & $\beta(S D)$ & $\chi^{2}$ & $p$ Value \\
\hline Intercept & $-7.331(0.877)$ & 69.95 & 0.0001 \\
Cumulative concentration & $0.079(0.031)$ & 6.38 & 0.0115 \\
Age of first exposure & $0.108(0.029)$ & 13.71 & 0.0002 \\
Tuberculosis & $1.59(0.609)$ & 0.83 & 0.0089 \\
\hline
\end{tabular}

ing silicosis correlated positively with cumulative exposure to respirable silica dust. The multiple logistic regression model can be expressed as follows:

$$
\begin{gathered}
\mathrm{p}=1 /(1+\exp (-((-7 \cdot 331)+0 \cdot 079 \mathrm{CUMCON} \\
+0 \cdot 108 \mathrm{AGE} 1+1.59 \mathrm{~TB}))) \\
\text { CUMCON }=\mathrm{C}^{\star} \mathrm{U}
\end{gathered}
$$

where:

$\mathrm{p}=$ The probability level of developing silicosis.

CUMCON = Cumulative exposure to respirable silica dust in units of $\mathrm{mg}$ years $/ \mathrm{m}^{3}$.

AGE 1 = Age of first exposure (y).

$\mathrm{TB}=$ Tuberculosis before silicosis developed.

$\mathrm{C}=$ Respirable concentration $\left(\mathrm{mg} / \mathrm{m}^{3}\right)$.

$\mathrm{U}=$ Duration of exposure $(\mathrm{y})$.

If the sensitivity of the model was $95 \%$, a probability level for classification of silicosis of $0.8 \%$ was derived. An exposure limit of $0.24 \mathrm{mg} / \mathrm{m}^{3}$ was estimated according to equations (1) and (2) when given a probability level for classification of silicosis as $0.8 \%$, a duration of exposure of 30 years, and TB as 0 (those without TB).

\section{Discussion}

Silicosis is a chronic occupational disease with a long period of latency and it is important to establish its relation to respirable dust. To determine respirable dust concentrations it is necessary to convert total dust concentration in historical surveillance and monitoring data to respirable dust concentration by making experiments on respirable and total dust concentrations. Our results showed that the ratio of respirable to total dust concentrations was 0.529 . It was assumed that changes in the ratio were small over various periods because working conditions and dust protective measures were stable. Estimates of respirable dust concentration were therefore derived from the total dust concentrations by applying a conversion factor of 0.529 .

The probability of developing silicosis was positively correlated with cumulative exposure to respirable silica dust (table 2 ). This would be consistent with published evidence. ${ }^{23}$ The less the sensitivity of the regression model, the better the protection of workers from silicosis. It was accepted that the sensitivity was $95 \%$. The age of first exposure was assumed to be 18 years according to the 12 th clause of the Act of Silicosis of the People's Republic of China, which stated that workers were ". . . not eligible to participate in dust work without being more than 18 years old." The duration of exposure was assumed as 30 years taking the duration of employment in a worker's whole life as $30-40$ years. The free silica content in respirable silica dust was $24 \cdot 7 \%$. A respirable dust concentration of 0.24 $\mathrm{mg} / \mathrm{m}^{3}$ was estimated based on these conditions. We conclude that the exposure limit of $0.24 \mathrm{mg} / \mathrm{m}^{3}$ would be safe allowing for epidemiological evidence. 
We thank Dr $M$ Jacobsen from the Institute of Occupational Medicine, Edinburgh, UK, Dr Mike Phillips, and Dr Xin Kai Lu, Centre for Advanced Studies, Australia for design and data processing. The cost was covered by a grant from the Ministry of Public Health of China.
1 SAS Institute. Logist procedure. In: Supplemental Library User's Guide, Version 5. Cary, NC: SAS Institute, 1986:662.

2 Jacobsen M, Rae S, Walton WH, Rogan JM. The relationship between pneumoconiosis and dust exposure in British coal mines. In: Walton WH, ed. Inhaled particles III. Old Woking, Surrey: Unwin Bros, 1971:903-19.

3 Hurley JF, Burs J, Copland L, Dodgson J, Jacobsen M. Coalworkers' simple pneumoconiosis and exposure to dust at 10 British coalmines. Br J Ind Med 1982;39:120-7.

Accepted 13 May 1991

\section{Inhalation Fever: A proposed unifying term for febrile reactions to inhalation of noxious substances}

Over the past several years there have been many publications that consider respiratory illnesses of farmers. ${ }^{1-3}$ Much of the interest has centred around the description of a febrile illness caused by exposure to organic dust that has been called several names including: grain fever, pulmonary mycotoxicosis, silo unloader's syndrome, and organic dust toxic syndrome (ODTS). There is now sufficient evidence to suggest that these febrile attacks are separate from allergic alveolitis. The physiological impact of the febrile illness on the lung is minimal whereas in allergic alveolitis one sees abnormal blood gases, chest radiographs, and pulmonary function tests. ${ }^{4}$

In the modern industrial era there has been extensive writing about febrile responses to the inhalation of metal fumes and dusts such as metal fume fever among welders and foundry workers. ${ }^{56} \mathrm{As}$ plastics emerged papers appeared describing febrile illnesses in those who work with complex polymers. ${ }^{7}$

The clinical picture of these inhalation ailments is similar. All have a latent period of several hours between the exposure and the onset of fevers, chills, malaise, myalgias, and chest tightness. Patients often have a leucocytosis with a left shift. ${ }^{289-11}$ There are reports of chemical pneumonitis and pulmonary oedema in some metal and plastic exposures and a single report suggesting more severe lung involvement after exposure to organic dust in an agricultural setting, but most reports suggest that little lung damage occurs. ${ }^{12-15}$

We are struck by the described similarities and believe that a generic term is best for this family of respiratory ailments. In the absence of a single aetiological agent for these very different exposures we think that the fevers and symptoms represent a common pathway in which the lung reacts to noxious substances. We suggest that they all be called inhalation fever, a term originating from $1978 .^{16}$ This avoids the colourful but confusing litany of names currently in use. Henceforth we propose that organic dust toxic syndrome, all the fume fevers, spelter shakes, mill fever, Monday fever, card room fever, and brass founders ague etc, be called simply Inhalation fever.

A RASK-ANDERSEN
Department of Occupational Medicine,
University Hospital,
S-75185 Uppsala, Sweden
D S PRATT
New York Center
for Agricultural Medicine and Health,
One Atwell Road, Cooperstown,
New York 13326, USA

1 Pratt DS, May JJ. Feed-associated respiratory illnesses in farmers. Arch Environ Health 1984;39:43-7.

2 Rask-Andersen A. Organic dust toxic syndrome among farmers. Br J Ind Med 1989;46:233-8.

3 Husman K, Terho E, Notkola V, Nuutinen J. Organic dust toxic syndrome among Finnish farmers. Am J Ind Med 1990;17: $79-80$.

4 Malmberg P, Rask-Andersen A, Höglund S, KolmodinHedman B, Guernsey J. Incidence of organic dust toxic syndrome and allergic alveolitis in Swedish farmers. Int Arch Allergy Appl Immunol 1988;87:47-54.

5 Brodie J. Welding fumes and gases: Their effect on the health of the worker. California and Western Medicine 1943;59:13-8.

6 Drinker P, Thomson RM, Finn K. Metal fume fever: IV. Threshold doses of zinc oxide, preventive measures, and the chronic effects of repeated exposures. J Ind Hyg 1927;9: 331-45.

7 Harris DK. Polymer fume fever. Lancet 1951;7814:1008-11.

8 Pratt DS, Stallones L, Darrow D, May J. Acute respiratory illness associated with silo unloading. Am J Ind Med 1986, 10:328.

9 Mueller E, Seger D. Metal fume fever: A review. J Emerg Med $1985 ; 2: 271-4$.

10 Armstrong C, Moore L, Hackler R, Miller G, Stroube R. An outbreak of metal fume fever. J Occup Med 1983;25:886-8.

11 Nuttal J, Kelly RJ, Smith BS, Whiteside CK Jr. Inflight toxic reactions resulting from fluorocarbon resin pyrolysis. Aerospace Medicine 1964;35:676-83.

12 Dula D. Metal fume fever. Journal of the American College of Emergency Physicians 1978;7:448-50.

13 Anthony J, Zamel N, Aberman A. Abnormalities in pulmonary function after a brief exposure to toxic metal fumes. Can Med Ass $J$ 1978;119:586-8.

14 Robbins J, Ware R. Pulmonary edema from tefion fumes. New Engl J Med 1964;271:360-1.

15 Yoshida K, Ando M, Araki S. Acute pulmonary edema in a storehouse of moldy oranges: A severe case of the organic dust toxic syndrome. Arch Environ Health 1989;44:382-4.

16 Editorial. Inhalation fevers. Lancet 1978;4:249-50. 